\title{
Assessing theoretical flow velocity profile and resistance in gravel bed rivers by field measurements
}

\author{
Vito Ferro, ${ }^{1}$ Paolo Porto ${ }^{2}$ \\ ${ }^{1}$ Department of Earth and Marine Science, University of Palermo; ${ }^{2}$ Department of Agriculture, Mediterranean \\ University of Reggio Calabria, Italy
}

\begin{abstract}
Previous studies showed that integrating a power velocity profile, deduced applying dimensional analysis and the incomplete self-similarity condition, the flow resistance equation for open channel flow can be obtained. At first, in this paper the relationship between the $\Gamma$ function of the power velocity profile, the channel slope and the Froude number, which was already empirically introduced in a previous paper, is now theoretically deduced. Then this relationship is calibrated using the field measurements of flow velocity, water depth and bed slope carried out in 101 reaches of gravel bed rivers available by literature. The proposed relationship for estimating $\Gamma$ function and the theoretical flow resistance equation are also tested by an independent dataset of 104 reaches of some gravel bed rivers (Fiumare) in Calabria region. Finally, the theoretically-based relationship for estimating the $\Gamma$ function is calibrated by the overall available database (205 reaches). In this way the three coefficients of the theoretically based $\Gamma$ function are estimated for a wide range of slopes $(0.1 \%$ $6.19 \%$ ) and hydraulic conditions (Froude number values ranging from 0.08 to 1.25 ).

In conclusion, the analysis shows that the Darcy-Weisbach friction factor for gravel bed rivers can be accurately estimated by the approach based on a power-velocity profile and the theoretically-based relationship proposed for estimating $\Gamma$ function. The analysis also points out a performance in estimating mean flow velocity better than that obtained in a previous study carried out by the authors.
\end{abstract}

\footnotetext{
Correspondence: Vito Ferro, Department of Earth and Marine Science, University of Palermo, via Archirafi 20, 90133 Palermo, Italy.

Tel.: +39.091.23897068 - Fax: +39.091.484035.

E-mail: vito.ferro@unipa.it
}

Key words: Flow resistance; gravel bed; dimensional analysis; self-similarity; flow velocity profile.

Received for publication: 13 November 2017.

Accepted for publication: 23 June 2018.

(C) Copyright V. Ferro and P. Porto, 2018

Licensee PAGEPress, Italy

Journal of Agricultural Engineering 2018; XLIX:810

doi:10.4081/jae.2018.810

This article is distributed under the terms of the Creative Commons Attribution Noncommercial License (by-nc 4.0) which permits any noncommercial use, distribution, and reproduction in any medium, provided the original author(s) and source are credited.

\section{Introduction}

Gravel bed channels with large-scale roughness (Bathurst, 1978; Bray, 1982; Lawrence, 1997), for which the uniform flow depth $h$ is of the same order of magnitude as the bed roughness height (Ferro and Giordano, 1991), which is frequently represented by the median bed diameter $d_{50}$, has received relatively little attention compared with the uniform flow in a channel with fine bed material. In this last case the uniform flow depth is much higher than the characteristic size of the particles arranged on the channel boundary and then a small-scale roughness condition occurs. According to Bathurst (1982) a channel has a cobble and boulder bed when the median size $d_{50}$ of its bed particles is greater than $64 \mathrm{~mm}$, the effects of vegetation are negligible and it is characterised by a transition or large-scale hydraulic condition which occurs for a ratio between the uniform flow depth $h$ and the bed diameter $d_{84}$, for which $84 \%$ of the bed particles are finer, less than or equal to 4 (Bathurst et al., 1981; Colosimo et al., 1988; Ferro, 1999; Reid and Hickin, 2008). In principle, the theoretical deduction of the flow-resistance law can be obtained by integration of a known flow-velocity distribution in the cross-section (Ferro, 1997, 2003a, 2003b; Powell, 2014). Linking velocity distribution and flow resistance continues to be one of the main challenges for uniform open channel flow hydraulics and the available theoretical results refer to defined boundary conditions (fixed bed) and some simple cross-section shapes (circular and rectangular very wide) since in these cases the velocity profile is known (Ferro and Pecoraro, 2000). For a small scale roughness-condition, occurring when the uniform flow depth is much higher that the characteristic size of the particle arranged on the channel boundary $\left(h / d_{50}>20\right.$ according to Bray (1987) or $h / d_{84}>4$ ), and a two-dimensional open channel flow, in the fully turbulent part of the inner region and in the outer region (Coleman and Alonso, 1983; Kirkgóz, 1989; Ferro and Pecoraro, 2000; Ferro, 2003a, 2003b) the velocity profile is described by a logarithmic distribution. Using some velocity profiles measured in a gravel bed channel, Ferro and Baiamonte (1994) positively checked the applicability of the logarithmic velocity profile to velocity measurements corresponding to a relative depth, which is equal to the ratio between the distance from the bottom $y$ and $h$, less than or equal to $y_{\max } / h$ being $y_{\max }$ the distance from the bottom where the maximum velocity occurs.

For a small-scale roughness-condition, the integration of the logarithmic velocity profile yields to a semi-logarithmic flow resistance law (Ferro, 2003a):

$$
\sqrt{\frac{8}{f}}=A_{o}+B_{o} \log \left(\frac{R}{k_{s}}\right)
$$

in which $f$ is the Darcy-Weisbach friction factor, $A_{o}$ and $B_{o}$ are two coefficients, $R$ is the hydraulic radius and $k_{s}$ is the roughness 
height. Marchand et al. (1984) observed that, for flow with depth sediment ratio $h / d_{84}$ in the range $1-4$, the velocity profile is Sshaped with near-surface velocities marked higher than those nearbed. For a large-scale roughness condition, following experimental investigations (Bathurst, 1988; Ferro and Baiamonte, 1994) stated that the shape of the velocity profile is affected by near bed local conditions, the velocity profile could not have a regular shape and its theoretical deduction could present some difficulties. For the two conditions of small- and large-scale roughness, the velocity profile in a gravel bed channel was deduced by Ferro and Pecoraro (2000) applying the incomplete self-similarity theory. The obtained power velocity distribution is able to reproduce experimental velocity profiles characterised by a maximum velocity occurring at the free surface. For transition and large-scale roughness condition, Ferro (1999) carried out an experimental investigation using a ground layer on which a number $N$ of boulders were arranged, varying the boulder concentration from 0 to 83 per cent. The following flow resistance law was established:

$$
\sqrt{\frac{8}{f}}=b_{o}+15.74 \log \left(\frac{h}{d_{84}}\right)
$$

in which the intercept $b_{o}$ becomes constant for boulder concentration values greater than $50 \%$. This last result stated that for high boulder concentration values ( $\geq 50 \%$ ) a quasi-smooth (skimming) flow occurs (Morris, 1959). Furthermore, the integration of the velocity distribution in the cross-section carried out by Ferro and Pecoraro (2000) confirmed that a semi-logarithmic flow resistance equation, like Eq. (2), is applicable for a gravel bed flume.

Notwithstanding many theoretical and experimental advances have been carried out, the Chezy, the Manning and the DarcyWeisbach uniform flow resistance equations continue to be the most commonly applied empirical formulas (Rouse and Ince, 1963; Bray, 1982; Powell, 2014):

$$
V=C \sqrt{R i}=\frac{i^{1 / 2} R^{2 / 3}}{n}=\sqrt{\frac{8 g R i}{f}}
$$

in which $V$ is the cross-section average velocity, $C$ is the Chezy coefficient $\left(\mathrm{m}^{1 / 2} \mathrm{~s}^{-1}\right), n$ is the Manning coefficient $\left(\mathrm{m}^{-1 / 3} \mathrm{~s}\right), i$ is the channel slope and $g$ is acceleration due to gravity.

In a previous paper (Ferro, 2017), applying the dimensional analysis and the self-similarity theory for a uniform open channel flow, the following power velocity distribution was deduced (Butera et al., 1993; Ferro, 1997; Ferro and Pecoraro, 2000):

$$
\frac{v}{u_{*}}=\Gamma\left(\frac{u_{*} y}{v_{k}}\right)^{\delta}
$$

in which $\mathrm{u}^{*}=\sqrt{g R i}$ is the shear velocity, $y$ is the distance from the bed at which local velocity $v$ is measured, $v_{\mathrm{k}}$ is the kinematic viscosity, $\Gamma$ is a function to be determined by velocity measurements and the exponent $\delta$ can be calculated by the following theoretical relationship (Castaing et al., 1990; Barenblatt, 1991):

$$
\delta=\frac{1.5}{\ln \operatorname{Re}}
$$

in which $R e=V h / v_{\mathrm{k}}$ is the flow Reynolds number. By integrating
Eq. (4) (Barenblatt, 1993; Ferro, 2017; Ferro and Porto, 2018) the following expression of the Darcy-Weisbach friction factor $f$ was obtained:

$f=8\left[\frac{2^{1-8} \Gamma \mathrm{Re}^{\delta}}{(\delta+1)(\delta+2)}\right]^{-2 /(1+8)}$

For $R e$ ranging from 2500 to 100,000 , setting $y=0.122 h$ the distance from the bottom at which the local velocity is equal to the cross-section average velocity $V$, Ferro (2017) obtained by Eq. (4) the following expression of $\Gamma$ :

$$
\Gamma=\frac{V}{u \cdot\left(\frac{u_{*} \alpha h}{v_{k}}\right)^{8}}
$$

where $\alpha$ is a coefficient, less than 1 , which takes into account that both a single velocity profile representing the whole cross-section is considered (i.e., the velocity profile is the mean profile in the cross-section) and the average velocity $V$ is located below the water surface.

The applicability of Eqs. (6) and (7) was tested by Ferro (2017) using field measurements of flow velocity, water depth, river width and bed slope for some Canadian mountain streams.

Ferro (2017), using the field measurements by Reid and Hickin (2008), empirically deduced the following equation for estimating the $\Gamma$ function:

$$
\Gamma=\frac{a F^{b}}{i^{c}}
$$

in which $a=0.313, b=1.1158$ and $c=0.5557$. Eq. (8) with the listed coefficient values is applicable for $1.7 \leq i \leq 7.5 \%$ and $F \leq 0.68$. A good agreement between the measured Darcy-Weisbach friction factor values $f$ and those calculated by Eqs.(6), (5) and (8) was established (Ferro, 2017); in particular $97.8 \%$ of the errors are less than or equal to $\pm 10 \%$.

The applicability of the empirical Eq. (8) with $a=0.3043$, $b=1.013$ and $c=0.5419$, in the range $0.11 \leq i \leq 6.19 \%$ and $0.18 \leq F \leq 1.25$, was confirmed by Ferro and Porto (2018) using the measurements carried out in 104 reaches of Calabrian gravel bed rivers (fiumare) with an high boulder concentration. Using the measurements of flow velocity, water depth, cross-section area, wetted perimeter and bed slopes carried out in 106 reaches of some rills modelled on an experimental plot, Di Stefano et al. (2017) obtained an empirical relationship for estimating the $\Gamma$ function having the same mathematical shape of Eq. (8). At first, in this paper the dimensional analysis and the self-similarity theory are used to theoretically deduce the $\Gamma$ function of the velocity profile. Then the theoretically deduced $\Gamma$ function is calibrated by field measurements of discharge, water depth and bed slope carried out in 101 reaches of gravel bed rivers by Bathurst $(1978,1985)$, Bray (1979), Griffiths (1981), Kellerhals (1967) and Thompson and Campbell (1979). The theoretical equation proposed to estimate the $\Gamma$ function and the flow resistance law (Eq. 6) are also verified by 104 independent field measurements carried out by Ferro and Porto (2017) in 104 reaches of some Calabrian gravel bed rivers (Fiumare). Finally, the theoretically-based relationship for estimating the $\Gamma$ function is calibrated by the overall available database (205 reaches) characterised by a wide range of slopes and hydraulic conditions. 


\section{Deducing the $\Gamma$ function of the power velocity profile by dimensional analysis}

For a uniform turbulent open channel flow in a gravel bed channel the local flow velocity distribution $v(y)$ along a given vertical is expressed by the following functional relationship (Barenblatt 1987, 1993; Ferro, 1997):

$\phi_{1}\left(\frac{d v}{d y}, y, h, d, u_{*}, i, \rho, \mu, g\right)=0$

in which $\phi_{1}$ is a functional symbol, $d$ is a characteristic diameter, $\rho$ is the water density and $\mu$ is the water viscosity. According to the П-theorem (Barenblatt, 1987), Eq. (9) can be rewritten in the following dimensionless form:

$$
\Pi_{1}=\phi_{2}\left(\Pi_{2}, \Pi_{3}, \Pi_{4}, \Pi_{5}, \Pi_{6}\right)
$$

where $\Pi_{1}, \Pi_{2}, \Pi_{3}, \Pi_{4}, \Pi_{5}, \Pi_{6}$ are dimensionless groups and $\phi_{2}$ is a functional symbol.

Using as dimensional independent variables $y, u^{*}$ and $\mu$, the following dimensionless groups are obtained:

$$
\begin{aligned}
& \Pi_{1}=\frac{y}{u \cdot d y} \frac{d v}{d y} \\
& \Pi_{2}=\frac{h}{y} \\
& \Pi_{3}=\frac{d}{y} \\
& \Pi_{4}=i \\
& \Pi_{5}=\frac{u \cdot y}{v_{k}} \\
& \Pi_{6}=\frac{g y}{u_{*}^{2}}
\end{aligned}
$$

Taking into account that In some cases, it turns out to be convenient to choose new similarity parameters - products of powers of the similarity parameters obtained in the previous step (Barenblatt, 1987), the following dimensionless group are obtained:

$\Pi_{2,3}=\frac{\Pi_{2}}{\Pi_{3}}=\frac{h}{y} \frac{y}{d}=\frac{h}{d}$

$\Pi_{5,3,2}=\Pi_{5} \Pi_{3} \Pi_{2,3}=\frac{u \cdot y}{v_{k}} \frac{d}{y} \frac{h}{d}=\frac{u \cdot h}{v_{k}}$

$\Pi_{6,2}=\sqrt{\frac{8}{f}} \frac{1}{\Pi_{6}^{1 / 2} \Pi_{2}^{1 / 2}}=\sqrt{\frac{8}{f}} \frac{u_{*}}{g^{1 / 2} y^{1 / 2}} \frac{y^{1 / 2}}{h^{1 / 2}}=\frac{\sqrt{\frac{8 u_{*}^{2}}{f}}}{g^{1 / 2} h^{1 / 2}}=\frac{V}{\sqrt{g h}}=F$

in which $F$ is the flow Froude number. Therefore, the functional relationship (10) can be rewritten in the following form:

$\Pi_{1}=\phi_{3}\left(\Pi_{2,3}, \Pi_{4}, \Pi_{5}, \Pi_{5,3,2}, \Pi_{6,2}\right)$ where $\phi_{3}$ is a functional symbol.

Introducing into Eq. (20) the expression of each dimensionless group, this functional relationship is obtained:

$\frac{y}{u_{*}} \frac{d v}{d y}=\phi_{4}\left(\frac{u_{*} y}{v_{k}}, \frac{u_{*} h}{v_{k}}, \frac{h}{d}, i, F\right)$

where $\phi_{4}$ is a functional symbol.

A phenomenon is defined self-similar in a given $\Pi_{n}$ dimensionless group when the functional relationship $\Pi_{1},=\phi\left(\Pi_{2}, \Pi_{3}, \ldots \ldots \ldots\right.$, $\left.\Pi_{n}\right)$, in which $\phi$ is a functional symbol, representing the physical phenomenon is independent of $\Pi_{\mathrm{n}}$. The self-similarity solutions of a problem are searched for boundary conditions, i.e., the behaviour of the function $\phi$ is studied for $\Pi_{n} \rightarrow 0$ and $\Pi_{n} \rightarrow \infty$. When the function $\phi$ tends to a finite limit which is different from zero, the phenomenon is not influenced by $\Pi_{n}$ and is expressed by the functional relationship $\Pi_{1},=\phi_{5}\left(\Pi_{2}, \Pi_{3}, \ldots \ldots \ldots, \Pi_{n-1}\right)$, in which $\phi_{5}$ is a functional symbol, and the self-similarity is named complete selfsimilarity in a given $\Pi_{\mathrm{n}}$ dimensionless group.

When the function $\phi$ has a limit equal to zero or tends to infinity, the phenomenon is expressed by the following functional relationship:

$\Pi_{1}=\Pi_{n}^{\beta} \phi_{6}\left(\Pi_{2}, \Pi_{3}, \ldots \ldots, \Pi_{n-1}\right)$

in which $\phi_{6}$ is a functional symbol and $\beta$ is a numerical constant. This instance is named incomplete self-similarity (ISS) in the parameter $\Pi_{n}$ (Barenblatt 1979, 1987).

Assuming the ISS in $u^{*} y / v_{\mathrm{k}}$ (Barenblatt and Monin, 1979; Barenblatt and Prostokishin, 1993; Butera et al., 1993; Ferro and Pecoraro, 2000; Ferro, 2017), Eq. (21) can be rewritten as:

$\frac{1}{u_{*}} \frac{d v}{d y}=\left(\frac{1}{y} \frac{u_{*} y}{v_{k}} \frac{v_{k}}{u_{*} y}\right)\left(\frac{u_{*} y}{v_{k}}\right)^{\delta} \phi_{7}\left(\frac{u_{*} h}{v_{k}}, \frac{h}{d}, i, F\right)$

in which $\phi_{7}$ is a functional symbol.

Rearranging Eq. (23) the following equation is obtained:

$\frac{1}{u_{*}} \frac{d v}{d y}=\left(\frac{u_{*}}{v_{k}}\right)\left(\frac{u_{*} y}{v_{k}}\right)^{\delta-1} \phi_{7}\left(\frac{u_{*} h}{v_{k}}, \frac{h}{d}, i, F\right)$

According to Eqs. (18) and (17), it results

$\frac{\Pi_{5,3,2}}{\Pi_{2,3}}=\frac{u \cdot h}{v_{k}} \frac{d}{h}=\operatorname{Re}$.

while Eqs. (19) and (17) allow to obtain the following equation:

$\Pi_{6,2}^{2} \Pi_{2,3} \frac{\gamma}{\left(\gamma_{s}-\gamma\right)}=F^{2} \frac{h}{d} \frac{\gamma}{\left(\gamma_{s}-\gamma\right)}=\frac{V^{2}}{g d} \frac{\gamma}{\left(\gamma_{s}-\gamma\right)}=\frac{g R i}{g d} \frac{8}{f} \frac{\gamma}{\left(\gamma_{s}-\gamma\right)}=\frac{8}{f} \frac{\gamma R i}{\left(\gamma_{s}-\gamma\right) d}=\frac{8}{f} \theta$

where $\theta$ is the Shields parameter which is dependent on Re* (Shields, 1936; Buffington and Montgomery, 1997; Di Stefano and Ferro, 2005). Taking into account that, according to Eq. (26) and (25), that the flow Froude number synthetises the effect of $h / d$ and 
Re*, Eq.(24) can be rewritten as follows:

$$
\frac{1}{u_{*}} \frac{d v}{d y}=\left(\frac{u *}{v_{k}}\right)\left(\frac{u * y}{v_{k}}\right)^{\delta-1} \phi_{7}(i, F)
$$

Integrating Eq.(27) the following power velocity distribution is deduced:

$$
\frac{v}{u_{*}}=\left[\begin{array}{ll}
\frac{1}{\delta} & \phi_{7}(i, F)
\end{array}\right]\left(\frac{u_{*} y}{v_{k}}\right)^{\delta}+C_{i}
$$

where $C_{i}$ is integration constant, which can be assumed equal to zero according to previous experimental results (Barenblatt and Protokishin, 1993; Butera et al., 1993; Ferro and Pecoraro, 2000). In conclusion, Eq.(28) can be rewritten as follows:

$$
\frac{v}{u .}=\Gamma(i, F)\left(\frac{u \cdot y}{v_{k}}\right)^{\delta}
$$

In other words, Eq. (29) is the theoretical demonstration that $\Gamma$ function is dependent on bed slope $i$ and flow Froude number $F$. Introducing Eq. (10) into Eq. (29) implies that an incomplete selfsimilarity hypothesis can be used, in the velocity distribution, respect to the channel bed slope and the flow Froude number.

\section{Field data}

\section{Calibration literature data set}

The calibration data set is constituted by field measurements of discharge, water depth and bed slope carried out in 101 reaches of gravel bed rivers by Bathurst (1978, 1985), Bray (1979), Griffiths (1981), Kellerhals (1967) and Thompson and Campbell (1979).

The measurements by Bathurst (1978) were carried out in 9 reaches of the River Tees in Great Britain. The bed slope ranged from 0.8 to $1.7 \%$, the flows were turbulent and subcritical $(0.17 \leq F \leq 0.45)$. Bathurst (1985) carried out the measurements in 36 reaches of some English gravel bed rivers. The bed slope ranged from 0.5 to $3.7 \%$, the flows were turbulent and subcritical $(0.15 \leq F \leq 0.76)$. The measurements by Bray (1979) were carried out in some Canadian gravel bed river reaches having a slope $i$ ranging from 0.2 to $1.5 \%$ and which were characterised by turbulent and subcritical flows. The measurements by Griffiths (1981) were carried out in 21 reaches of some rivers in New Zeeland. The bed slope ranged from 0.1 to $1.1 \%$, the flows were turbulent and subcritical $(0.08 \leq F \leq 0.56)$. The measurements by Kellerhals (1967) were carried out in some Canadian gravel bed river reaches having a slope $i$ ranging from 0.3 to $0.7 \%$ and characterised by flow which were turbulent and having Froude numbers $F$ ranging from 0.60 to 0.79. The measurements reported in Thompson and Campbell (1979) were carried out in 22 reaches. The bed slope ranged from 0.8 to $5.2 \%$, the flows were turbulent and with a Froude number ranging from 0.47 to 0.96 .

\section{Validation data set}

The investigated rivers are located in Calabria (Southern Italy) and have hydraulic and geometric characteristics typical of the water courses belonging to the Italian Apennine mountain chain. These gravel bed rivers can be ascribed to the category better known as fiumare (Sabato and Tropeano, 2004) that show typical high gradients and short lengths.

Three validation datasets have been used in this experimental work (Figure 1). The first database is obtained by the available measurements provided by the Italian Hydrographic Service

\begin{tabular}{|c|c|c|c|c|c|}
\hline River & Cross section & CODE & River & Cross section & CODE \\
\hline Alaco & Pirrella & 21 & Crati & Conca & 8 \\
\hline Alli & Orso & 17 & Esaro & La Musica & 10 \\
\hline \multirow{2}{*}{ Amato } & Marino & 24 & Garga & Torre Garga & 12 \\
\hline & Licciardi & 25 & Lao & Pie' di borgo & 28 \\
\hline \multirow{2}{*}{ Ancinale } & Crisura & 20 & Mucone & Cecita & 11 \\
\hline & Razzona & 19 & \multirow{2}{*}{ Savuto } & Ponte Savuto & 27 \\
\hline Corace & Grascio & 18 & & Poverella & 26 \\
\hline Coscile & Camerata & 9 & Simeri & Vincolise (Ponte vecchio) & 16 \\
\hline
\end{tabular}

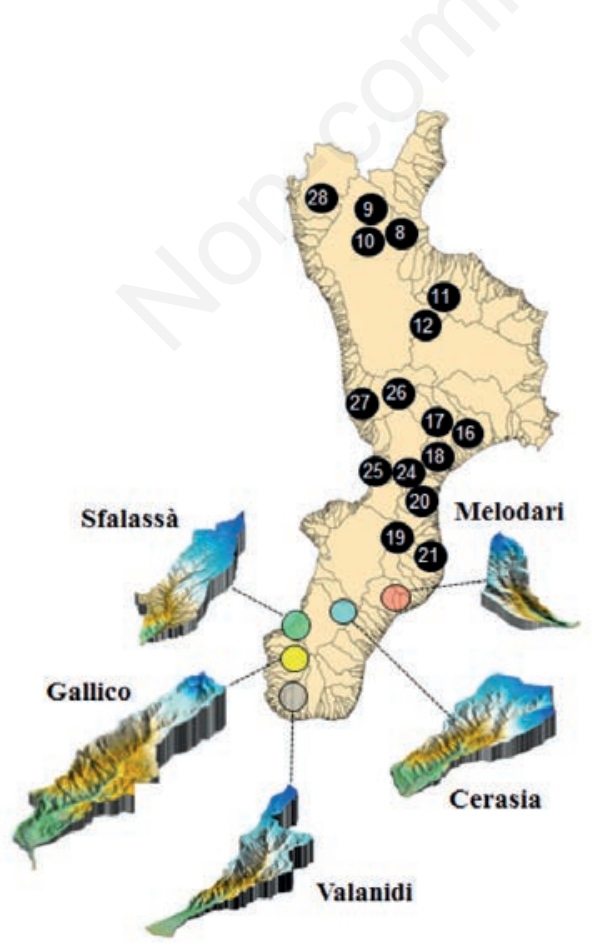

The Hydrographic Service dataset

Colosimo et al. (1988) dataset

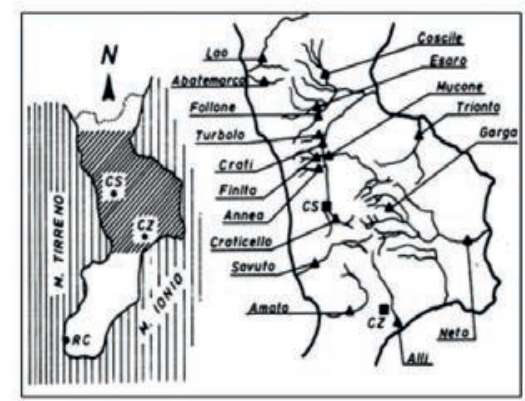

Figure 1. Location of the gravel bed rivers used for validating the flow resistance law. 
(SIMI) for 16 cross sections. The second database make use of the data provided by Colosimo et al. (1988) for 29 individual cross sections, while the third one required specific field activities undertaken on 59 individual cross sections located in 5 different natural streams (Ferro and Porto, 2018). From the early 1920s to the beginning of $1950 \mathrm{~s}$, SIMI published stage-discharge relationships for many rivers in the country.

These relationships have been deduced using independent measurements of mean cross-section velocity operated in stable cross sections. In this study, long-term measurements of mean cross-section velocity available for 13 rivers (16 cross sections) located in Calabria (Figure 1) have been used. The measurements by SIMI are characterised by bed slope ranging from 0.16 to $6.0 \%$, the flows are always turbulent and with a Froude number ranging from 0.18 to 1.25 .

Colosimo et al. (1988) made an investigation on 29 selected cross sections, free from obstacles, located in 17 Calabrian streams as reported in Figure 1. In order to obtain a reliable estimate of mean flow velocity in each cross section, a set of point measures were carried out with a current meter.

The measurements by Colosimo et al. (1988) are characterised by bed slope ranging from 0.22 to $1.9 \%$, the flows are always turbulent and with a Froude number ranging from 0.27 to 1.19 .

Five field campaigns have been undertaken in 2011, 2012, and 2013 for surveying 5 torrents (T. Cerasia, T. Gallico, T. Melodari, T. Sfalassà, and T. Valanidi) (see Figure 1) (Ferro and Porto, 2018). A total of 59 cross sections have been selected based on the main assumption of quasi-uniform flow condition over a straight reach, having a length ranging from 50 to $100 \mathrm{~m}$, containing the cross sections. The cross section located in the middle of each reach was assumed representative of the entire reach and was surveyed for measurements of flow velocity and discharge.

The measurements of discharge and flow velocity have been made with a 3D FlowTracker (see Figure 2) that uses the proven technology of the SonTek/YSI acoustic Doppler velocimeter (ADV) from a simple handheld interface. The distance of the field worker from the measurement cross-section allowed to avoid any interference with the ADV. Further details are reported in Ferro and Porto (2018). The measurements by Ferro and Porto (2018) are characterised by bed slope ranging from 0.11 to $6.19 \%$ and 0.18 $\leq F \leq 1.25$.

\section{Calibrating and testing the theoretical flow resist- ance law}

\section{Calibrating the theoretical flow resistance law by litera- ture data}

Using the measurements corresponding to 101 gravel bed reaches of the literature the following rough equation for estimating the $\Gamma$ function was determined (Figure 3):

$$
\Gamma=0.2808 \frac{F^{1.0459}}{i^{0.5499}}
$$

which is characterised by a coefficient of determination equal to 0.996 and it is applicable for $0.1 \leq i \leq 5.2 \%$ and for subcritical flows $(0.08 \leq F \leq 0.96)$.

Eq. (30) coupled with Eq. (6) and Eq. (5) allows estimating the
Darcy-Weisbach friction factor taking into account the effects of flow condition $(F)$ and channel slope. Figure 4 shows the comparison between the values of the Darcy-Wesbach friction factor $f$ obtained by literature data and those calculated by Eqs. (6), (5) and (30).

The agreement between the measured $f_{m}$ and calculated $f_{c}$ values was characterised by a root mean square error RMSE:

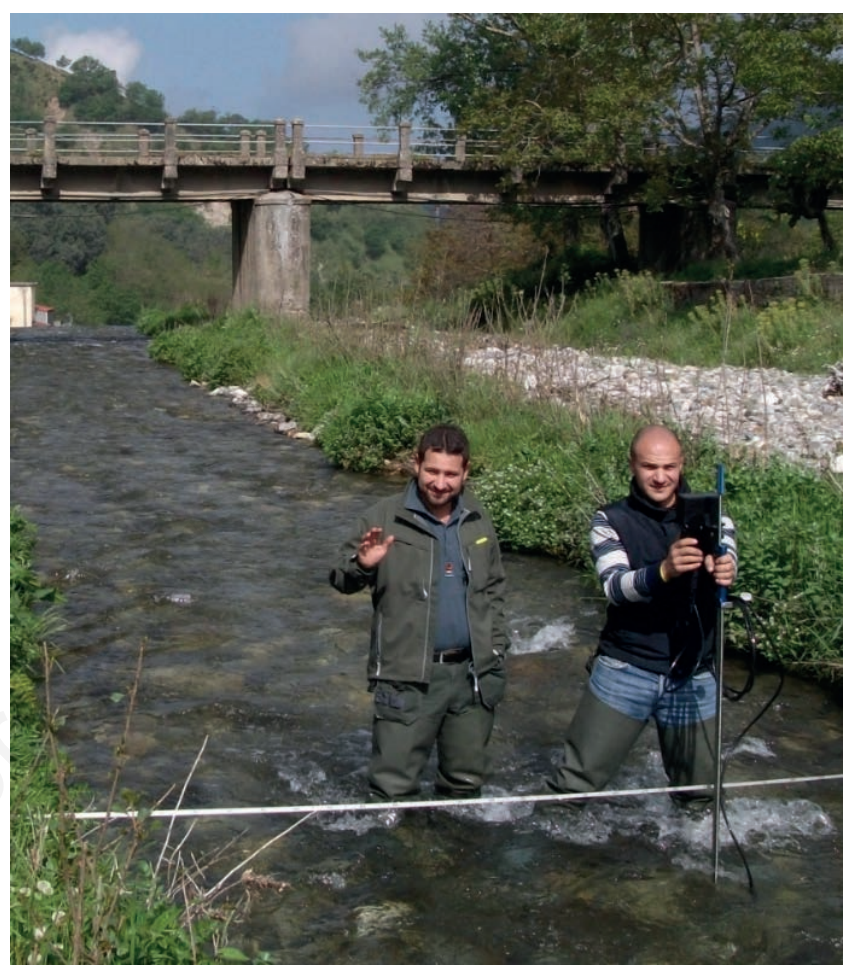

Figure 2. Measurement of discharge using the acoustic Doppler velocimeter in one of the selected cross-sections.

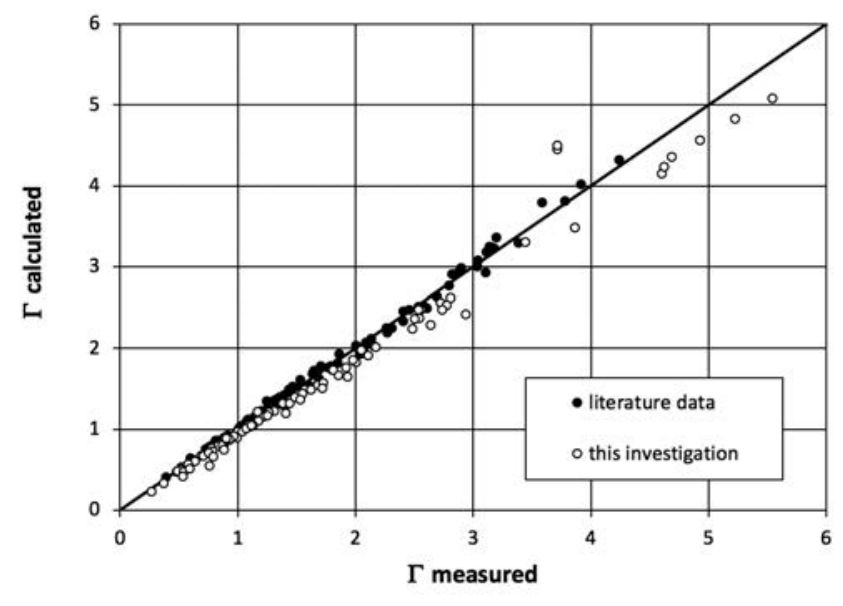

Figure 3. Comparison between measured $\Gamma$ values and those calculated by Eq. (30). 
$R M S E=\sqrt{\frac{\sum_{i=1}^{n}\left(f_{c}-f_{m}\right)^{2}}{N}}$

in which $N$ is the number of measurements. The RMSE describes the difference between model predictions and variable measurement in the units of the variable. The smaller the RMSE, the closer the predicted values are to the measured values.

The agreement between the measured $f_{m}$ values and those $f_{c}$ calculated by Eqs. (6), (5) and (30) is characterised by a RMSE equal to 0.05 . Furthermore the friction factor values calculated by Eqs. (6), (5) and (30) are characterised by estimate errors which are always less than or equal to $\pm 20 \%$.

\section{Testing the theoretical flow resistance law by Calabrian gravel bed data}

For testing the applicability of Eqs. (6), (5) and (30) the complete validation dataset is used. Figure 3 shows a good agreement between the $\Gamma$ values obtained by the independent dataset of 104 field measurements carried out in Calabrian gravel be rivers and Eq. (30).

Figure 4 shows a good agreement between the 104 measured Darcy-Weisbach friction factor values $f$ and those calculated by Eqs. (6), (5) and (30). This last agreement is characterised by a $R M S E$ equal to 0.4 and $79 \%$ of the estimate errors are less than or equal to $\pm 20 \%$.

The agreement between the overall measured Darcy-Weisbach friction factor values (205 data) and those calculated by Eqs. (6), (5) and (8), with $a=0.3043, b=1.013$ and $c=0.5914$ estimated by Ferro and Porto (2018), is characterised by RMSE equal to 0.17 and $94 \%$ of the estimate errors are less than or equal to $\pm 20 \%$.

Finally, using the measurements corresponding to the literature data (101 gravel bed reaches) and the Calabrian gravel bed rivers (104 data) the following equation is determined:

$$
\Gamma=0.3145 \frac{F^{1.033}}{i^{0.5304}}
$$

Eq. (32) is applicable in a wide range of bed slope $(0.11 \leq i$ $\leq 6.19 \%)$ and flow Froude number $(0.08 \leq F \leq 1.25)$.

The agreement between the 205 measured $f$ values and those calculated by Eqs. (6), (5) and (32) (Figure 5) is characterised by RMSE equal to 0.177 and $95 \%$ of the estimate errors are less than or equal to $\pm 20 \%$. The comparison between Eq. (32) and Eq. (8) with $a=0.3043, b=1.013$ and $c=0.5419$ (Ferro and Porto, 2018) shows that the ranges of slope $i$ and $F$ corresponding to the available data sets affect the estimate of the empirical coefficients $a, b$ and $c$.

The performances of the proposed theoretical equation for estimating $\Gamma$ function was also evaluated comparing the measured mean cross-section velocity values $V$ with those calculated by Eqs. (3), (6), (5) and (32). Figure 6, showing a good agreement between the measured $V$ values and the calculated ones, confirms the accuracy of this $\Gamma$ estimate criterion. Finally, the comparison between Figure 1 and Figure 9 by Ferro and Porto (2018) demonstrates that Eq. (32) allows the best performance in estimating mean flow velocity.

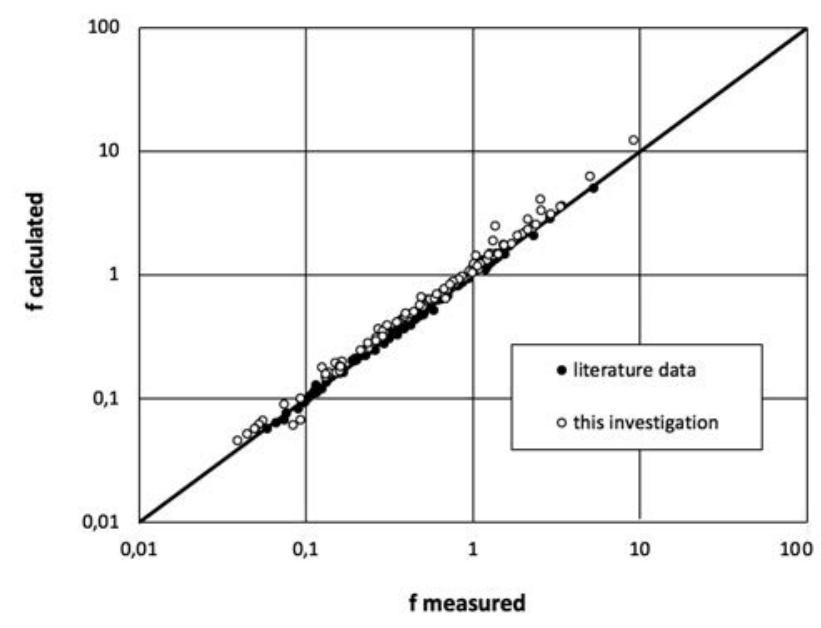

Figure 4. Comparison between measured $f$ values and those calculated by Eqs. (6), (5) and (30).

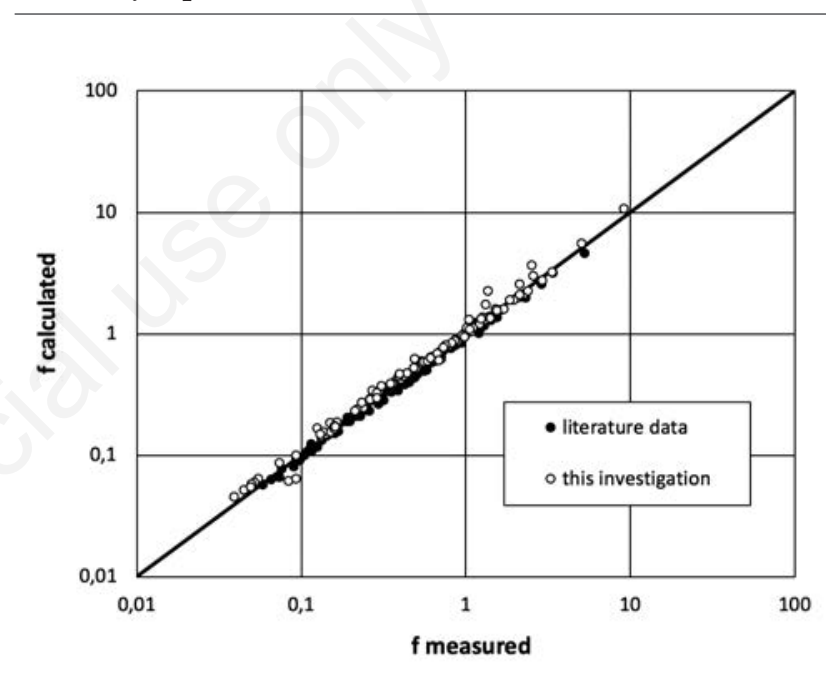

Figure 5. Comparison between measured $f$ values and those calculated by Eqs. (6), (5) and (32).

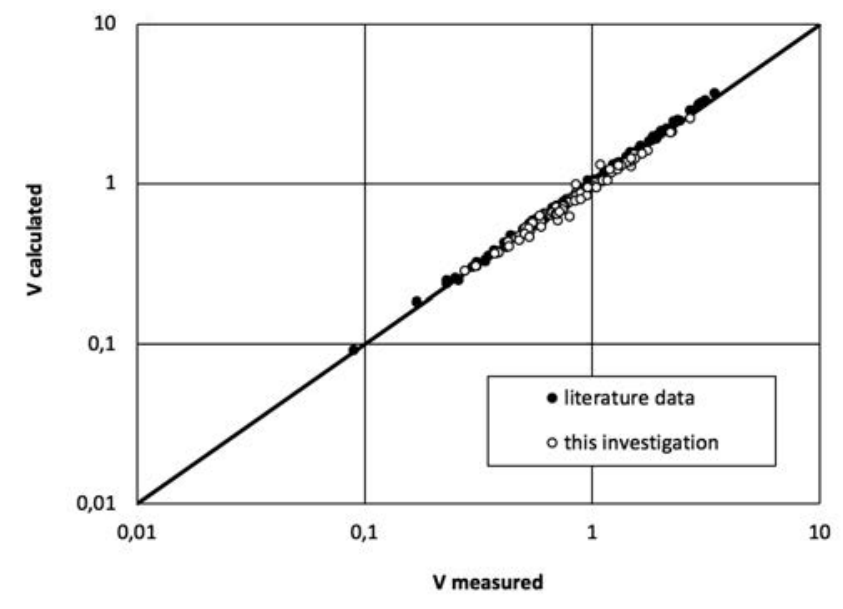

Figure 6. Comparison between measured $V$ values and those calculated by Eqs. (3), (6), (5) and (32). 


\section{Conclusions}

The flow resistance law was theoretically derived only for some simple cross-section shapes and under defined boundary condition since in these cases the flow-velocity profile is known.

In this paper, applying the dimensional analysis and the incomplete self-similarity hypothesis, the relationship between the $\Gamma$ function of the power velocity distribution, the channel bed slope and the flow Froude number was theoretically deduced.

The deduced theoretical equation for estimating the $\Gamma$ function of the power velocity profile was calibrated using available field measurements of flow velocity, water depth, cross-section area, wetted perimeter and bed slopes carried out in 101 gravel bed rivers. This equation was also positively tested by independent field measurements (104 data) carried out in Calabrian gravel bed rivers. This last analysis showed that the calibrated Eq. (30), coupled with Eq. (6) and Eq. (5), allows to calculate Darcy-Weisbach friction factor values which are characterised by estimate errors that for $94 \%$ of the calculated values are less than or equal to $\pm 20 \%$.

The theoretical $\Gamma$ function was also calibrated using all available measurements for gravel bed rivers (205 data) obtaining Eq. (32) which is applicable for the widest range of bed slope $(0.11 \leq i$ $\leq 6.19 \%)$ and flow Froude number $(0.08 \leq F \leq 1.25)$. This choice is justified by the circumstance that the ranges of slope $i$ and $F$ corresponding to the available data sets affect the estimate of the empirical coefficients $a, b$ and $c$ of Eq. (8).

The new equation (Eq. 32) for estimating the theoretical $\Gamma$ function allows to calculate Darcy-Weisbach friction factor values which are characterised by estimate errors that for $95 \%$ of the calculated values are less than or equal to $\pm 20 \%$. Therefore, Eq. (32) is the best equation for estimating $\Gamma$ values for a gravel bed river and allows also to improve, respect to a previous study, the performance of the mean flow velocity estimate.

In conclusion, the incomplete self-similarity approach for the velocity profile and the proposed theoretical equation for estimating $\Gamma$ function allowed an accurate estimate of both the DarcyWeisbach friction factor and the mean flow velocity.

\section{References}

Barenblatt G.I. 1979. Similarity, self-similarity and intermediate asymptotics. Consultants Bureau, New York, NY, USA.

Barenblatt G.I. 1987. Dimensional analysis. Gordon\&Breach, Science Publishers Inc., Amsterdam, The Netherlands.

Barenblatt G.I. 1991. On the scaling laws (incomplete self-similarity with respect to Reynolds numbers) for the developed turbulent flows in tubes. C.R. Acad. Sci. Ser. II 13:307-12.

Barenblatt G.I. 1993. Scaling laws for fully developed turbulent shear flows, part 1, Basic hypothesis and analysis. J. Fluid Mechan. 248:513-20.

Barenblatt G.I., Monin A.S. 1979. Similarity laws for turbulent stratified flows. Arch. Ration. Mech. Anal. 70:307-17.

Barenblatt G.I., Prostokishin V.M. 1993. Scaling laws for fully developed turbulent shear flows, part 2, Processing of experimental data. J. Fluid Mechan. 248:521-9.

Bathurst J.C. 1978. Flow resistance of large-scale roughness. J. Hydr. Engine. ASCE 104:1587-603.

Bathurst J.C. 1982. Flow resistance in boulder-bed streams. In: Hey, R.D., Bathurst, J.C., Thorne, C.R. (Eds.), Gravel-bed Rivers. Wiley, Chichester, UK, pp 443-462.

Bathurst J.C. 1985. Flow resistance estimation in mountain rivers.
J. Hydr. Engine. ASCE 111:625-43.

Bathurst J.C. 1988. Velocity profile in high-gradient, boulder-bed channels. pp 29-34 in Proc. International Conference on Fluvial Hydraulics, IAHR, Budapest, Hungary.

Bathurst J.C., Li R.H., Simons D.B. 1981. Resistance equations for large-scale roughness. J. Hydr. Engine. ASCE 107:1593-613.

Bray D.I. 1979. Estimating average velocity in gravel bed rivers. J. Hydr. Engine. ASCE 105:1103-22.

Bray D.I., 1982. Flow resistance in gravel-bed rivers. In: Hey, R.D., Bathurst, J.C., and Thorne, C.R. (Eds.), Gravel-Bed Rivers. Wiley, Toronto, Canada, pp 109-132.

Bray D.I. 1987. A review of flow resistance in gravel bed rivers. pp 23-57 in Proc. of the Workshop "Leggi morfologiche e loro verifiche di campo". Ed. Bios, Cosenza, Italy.

Buffington J.M., Montgomery D.R. 1997. A systematic analysis of eight decades of incipient motion studies with special reference to gravel-bedded rivers. Water Resour. Res. 33:1993-2029.

Butera L., Ridolfi L., Sordo S. 1993. On the hypothesis of self-similarity for the velocity distribution in turbulent flows. Excerpta 8:63-94.

Castaing B., Gagne Y., Hopfinger E.J. 1990. Velocity probability density functions of high Reynolds number turbulence. Phisica D 46:177-200.

Coleman N.L., Alonso C.V. 1983. Two-dimensional channel flows over rough surfaces. J. Hydr. Engine. ASCE 109:175-88.

Colosimo C., Copertino V.A., Veltri M. 1988. Friction factor evaluation on gravel bed rivers. J. Hydr. Engine. ASCE 114:861-9.

Di Stefano C., Ferro V. 2005. Storia ed attualità dell'Abaco di Shields. Riv. Ing. Agr. 1:65-78.

Di Stefano, C., Ferro, V., Palmeri, V., Pampalone, V. 2017. Flow resistance equation for rills. Hydrological Processes, 31, 27932801, DOI: 10.1002/hyp.11221.

Ferro V. 1997. Applying hypothesis of self-similarity for flowresistance law of small-diameter plastic pipes. J. Irrig. Drain. Engine. ASCE 123:175-9.

Ferro V. 1999. Friction factor for gavel-bed channel with high boulder concentration. J. Hydr. Engine. ASCE 125:771-8.

Ferro V. 2003a. ADV measurements of velocity distributions in a gravel-bed flume. Earth Surf. Process. Landforms 28:707-22.

Ferro V. 2003b. Flow resistance in gravel-bed channels with largescale roughness. Earth Surf. Process. Landforms 28:1325-39.

Ferro V. 2017. New flow resistance law for steep mountain streams based on velocity profile. J. Irrig. Drain. Engine. ASCE 143: 04017024, 1-6.

Ferro V., Baiamonte G. 1994. Flow velocity profiles in gravel bed rivers. J. Hydr. Engine. ASCE 120:60-80.

Ferro V., Giordano G. 1991. Experimental study of flow resistance in gravel bed rivers. J. Hydr. Engine. ASCE 117:1239-46.

Ferro V., Pecoraro R. 2000. Incomplete self-similarity and flow velocity in gravel bed channels. Water Resour. Res. 36:2761-9.

Ferro V., Porto P. 2018. Applying hypothesis of self-similarity for flow resistance law in Calabrian gravel-bed rivers. J. Hydr. Engine. ASCE 144:04017061, 1-11.

Griffiths G.A. 1981. Flow resistance in coarse gravel-bed rivers. Proc. ASCE J. Hydr. Div. 107:899-916.

Kellerhals R. 1967. Stable channels with gravel-paved bed. Proc. ASCE J. Waterways Harbour Div. 93:63-84.

Kirkgóz M.S. 1989. Turbulent velocity profiles for smooth and rough open channel flow. J. Hydr. Engine. ASCE 115:1543-61.

Lawrence D.S.L. 1997. Macroscale surface roughness and frictional resistance in overland flow. Earth Surf. Process. Landforms 22:365-82.

Marchand J.P., Jarrett R.D., Jones L.L. 1984. Velocity profile, 
water surface slope, and bed material size for selected streams in Colorado. US Geological Survey, Open-File Report 84-773.

Morris H.M. 1959. Design methods for flow in rough conduits. J. Hydr. Engine. ASCE 87:43-62.

Powell D.M. 2014. Flow resistance in gravel-bed rivers: Progress in research. Earth-Sci. Rev. 136:301-38.

Reid D.E., Hickin E.J. 2008. Flow resistance in steep mountain streams. Earth Surf. Process. Landforms 33:2211-40.

Rouse H., Ince S. 1963. History of hydraulics. Dover Publications,
New York, NY, USA.

Sabato L., Tropeano M. 2004. Fiumara: a kind of high hazard river. Physics Chem. Earth 29:707-15.

Shields A. 1936. Anwendung der Aenlichkeitsmechanik und der Turbolenzforschung auf die Geschiebebewegung. Mitteil, PVWES, Heft 26, Berlin, Germany.

Thompson S.M., Campbell P.L. 1979. Hydraulics of a large channel paved with boulders. J. Hydraul. Res. 17:341-54. 